\title{
COMO FAZER UM SANTO: AS BIOGRAFIAS DEVOTAS COMO ESTRATÉGIA DE CANONIZAÇÃO NO SÉCULO XVII
}

\author{
Camila Corrêa e Silva de Freitas*
}

\begin{abstract}
Resumo: No século XVII, as publicações biográficas dos pretendentes à santidade faziam parte da estratégia dos grupos de apoio para obter a canonização de seus candidatos. A Companhia de Jesus, tanto na Europa quanto no Brasil, também lançou mão deste expediente para promover seus primeiros santos, nem sempre com sucesso. A partir da análise de alguns casos de processos de canonização que se desenrolaram no século XVII, procuramos relacionar o volume de publicações biográficas de caráter hagiográfico à força da causa de canonização e ao grau de mobilização e pressão dos grupos de apoio.
\end{abstract}

Palavras-chave: Canonização, século XVII, biografias, Companhia de Jesus, José de Anchieta.

How to make a saint: the pious biographies as canonization strategy in the seventeenth century

Abstract: In the seventeenth century, the biographical publications of the pretenders to holiness were part of the strategy of supporting groups for the canonization of their candidates. The Society of Jesus, both in Europe and in Brazil, also made use of this expedient to promote its early saints, not always successfully. From the analysis of some cases of canonization processes that unfolded in the seventeenth century, we intended to relate the volume of hagiographic-biographical publications to the strength of the cause of canonization and the degree of mobilization and pressure of the supporting groups.

Keywords: Canonization, seventeenth century, biographies, Society of Jesus, José de Anchieta.

* Doutoranda no Programa de Pós-Graduação em História Social da Faculdade de Filosofia, Letras e Ciências Humanas - Universidade de São Paulo (FFLCH/ USP); Bolsista Capes (Programa de Doutorado Sanduíche no Exterior - PDSE) Recebido em: 08/10/2013 - Aceito em: 29/05/2014. 
$|170|$

Como fazer um santo: as biografias devotas...

Cómo hacer un santo: las biografías piadosas como estrategia de canonización en el siglo XVII

Resumen: En el siglo XVII las publicaciones biográficas de los pretendientes a la santidad eran parte de la estrategia de grupo de apoyo para la canonización de sus candidatos. La Compañía de Jesús, tanto en Europa como en Brasil, también hizo uso de este recurso para promover sus primeros santos, no siempre con éxito. A partir del análisis de algunos casos de procesos de canonización que tienen lugar en el siglo XVII, tratamos de relacionar el volumen de publicaciones biográficas de carácter hagiográfico para forzar la causa de canonización y el grado de movilización y presión de los grupos de apoyo.

Palabras clave: Canonización, siglo XVII, biografías, Sociedad de Jesús, José de Anchieta.

Em 1625, saía da casa de impressão de Pierre de la Court, em Bordeaux, a décima segunda biografia publicada na Europa sobre a vida, os milagres e a fama de santidade do padre jesuíta José de Anchieta, morto quase trinta anos antes na província brasileira da Companhia de Jesus. Não era um fato particularmente extraordinário, afinal a publicação de "vidas devotas" de candidatos a santos revelara-se um grande filão do crescente mercado editorial europeu desde o século anterior ${ }^{1}$. O que nos parece interessante, contudo, é que a publicação de tal quantidade de biografias sobre Anchieta no início do século XVII ocorria em paralelo aos esforços

\footnotetext{
1 Entendemos por "vidas devotas" o gênero literário biográfico que se desenvoveu sobremaneira entre os séculos XVI e XVII na Europa sobre as vidas de homens e mulheres que morreram em "odores de santidade", mas que não haviam sido oficialmente reconhecidos como santos pela Igreja Católica Romana, diferenciando-se assim das hagiografias, narrativas biográficas sobre indivíduos já canonizados oficialmente. Ver Gotor (2004); sobre o mercado de impressos na Europa e sua relação com os jesuítas ver Van Damme (2007); as biografias sobre Anchieta começaram a ser publicadas em 1617. As impressas no século XVII estão listadas na nota 20. Se considerarmos as biografias que ficaram manuscritas, podemos acrescentar mais três: o primeiro texto sobre a vida e morte de Anchieta, escrito pelo padre Quirício Caxa logo após a morte daquele, a obra do padre Pedro Rodrigues, de 1606, que serviu de base para a biografia do padre Beretário e outras sucessivas, e uma cópia da biografia do padre Rodrigues feita por Christóvão de Sousa Coutinho em 1620.
} 
dos jesuítas do Brasil em promover a introdução da causa de canonização do companheiro, confirmada oficialmente pelo papa em abril de 1624 (STANO, 1979:5).

Oempenho em fazer um santo não era específico da província jesuítica brasileira, nem mesmo da Companhia de Jesus. O século XVII viu serem introduzidas na Santa Sé 276 causas em prol da canonização de homens e mulheres, apesar de apenas 24 deles terem sido efetivamente promovidos aos altares. O culto público a indivíduos considerados santos era então uma prática social já enraizada nas comunidades católicas européias, assim como a busca de sua canonização junto às autoridades competentes era expediente comum ${ }^{2}$.

A santidade, enquanto fenômeno social, não é uma exclusividade da cultura católica, mas é da santidade católica que trataremos aqui. Em sua dimensão religiosa, a santidade manteve, praticamente desde princípios do cristianismo, o mesmo significado geral: designa aqueles e aquelas que alcançaram uma relação de proximidade com Deus e que desempenham uma função de dupla mediação entre o mundo natural/humano e o mundo sobrenatural/ divino, isto é, a revelação da vontade de Deus aos homens através de visões e profecias, e a intercessão junto a Deus a favor dos homens, através de milagres, por exemplo ${ }^{3}$. Os critérios adotados por uma comunidade para atribuir o caráter da santidade a um indivíduo variaram muito ao longo do tempo e das circunstâncias históricas. De fato, a percepção social da santidade é fruto de uma construção cultural, histórica e ideológica profundamente ligada às dinâmicas conjunturais vividas pela sociedade que constrói tal percepção. O reconhecimento e a promoção do reconhecimento de

${ }^{2}$ Um exemplo do interessante estudo sociológico de Pierre Delooz nos permite perceber que o culto púbico a santos cristãos era uma prática religiosa muito comum bem antes do século XVII. Segundo Delooz (1976), entre os anos de 993 e 1234, quinhentas pessoas foram canonizadas por igrejas locais e mais 73 o foram pela autoridade pontifícia.

${ }^{3}$ Ver o estudo de referência sobre a santidade cristã de Sofia Boesch Gajano, "La santità". Gajano (1999). 
um indivíduo como santo, ou seja, como alguém excepcional, de poderes sobre-humanos, intermediário entre os homens e Deus, tem sua origem nas circunstâncias sociais, políticas, culturais e econômicas vividas pelos grupos que o reconhecem ${ }^{4}$.

Tomando como referência a periodização feita por Peter Burke (1987) em sua análise da santidade moderna, nos deparamos com 55 indivíduos que foram elevados ao panteão celeste entre 1588 e $1767^{5}$. Os perfis sociais dos santos formalmente reconhecidos pela Santa Sé indicam que a ascensão ao altar não era resultado apenas da análise de critérios religiosos. Entre as 55 pessoas que foram canonizadas no período considerado, a grande maioria delas é originária da península itálica ou do império espanhol, pertencentes a ordens religiosas e/ou membros de famílias aristocráticas. Se considerarmos que nesta época a Espanha dominava boa parte do território italiano, parece razoável afirmar que um dos elementos que influenciava o reconhecimento oficial da santidade nesse período era a força política dos castelhanos e a estreiteza de seus laços com a Santa Sé (GOTOR, 2004: 93-94).

Ser fundador de uma ordem religiosa também se apresentava como um critério significativo para a canonização, uma vez que do total de 55, doze indivíduos se encaixam nessa descrição. É bastante provável que a preferência pontifícia por estes candidatos estivesse ligada ao interesse da Igreja de Roma em reforçar sua estrutura eclesiástica, representada pelas ordens e congregações em seus

\footnotetext{
${ }^{4}$ Neste artigo nos filiamos à análise sociológica da história da santidade apresentada por Pierre Delooz (1976) e Jean-Michel Sallmann (1997). Ver também Gajano (1999).

${ }^{5}$ Para este artigo tomamos como referência para o estudo da santidade moderna o artigo de Peter Burke, "How to be a Counter-Reformation saint" e o livro de Miguel Gotor, "Chiesa e santità nell'Italia moderna". Tal "demografia celeste" foi contabilizada por Burke considerando o período da retomada das canonizações pontifícias entre 1588, após um hiato que durou 65 anos, e 1767, último ano antes de uma nova paralisação das canonizações que durou 40 anos. Burke (1987). Também nos utilizamos da contagem de Gotor (2004) do período entre 1519 e 1758, 52 canonizações.
} 
diversos tipos de inserção social, visto o sensível enfraquecimento do catolicismo romano na Europa desde as reformas protestantes e o início das guerras de religião (SALLMANN, 1997:336). Contudo, é preciso também considerar que o elevado número de canonizações de sujeitos oriundos de ordens religiosas ou do clero secular nesse período, mais de quarenta no total de 55, inclusive os fundadores, é resultado da atuação de "grupos de pressão", em geral formados por membros da mesma ordem ou diocese do candidato. Bem estruturados, funcionais e persistentes o suficiente para levar adiante longos e custosos processos eclesiásticos, tais grupos dispunham com mais facilidade de recursos financeiros (obtidos muitas vezes de doações das várias províncias da ordem), competência canônica e crédito moral do que promotores de santos laicos ${ }^{6}$.

As ordens religiosas mais jovens se destacaram no panteão celeste moderno, principalmente a Companhia de Jesus, que conseguiu canonizar seis de seus membros entre os séculos XVII e XVIII, quase tantos quantos os santos provenientes de ordens mais antigas, como a dos franciscanos e a dos dominicanos ${ }^{7}$. De fato, para as novas ordens religiosas, a canonização de seus membros, começando pelo fundador, era um elemento central para fortalecer seu poder e prestígio dentro da comunidade eclesiástica e pôr à sombra quaisquer discordâncias quanto às suas práticas religiosas ou interpretações teológicas (GOTOR, 2004: 97).

Alcançar os altares católicos no século XVII, contudo, não era uma tarefa fácil nem simples. Desde 1234, quando a Igreja de Roma impôs a prerrogativa papal para a consagração oficial dos santos, a Europa católica assistiu a uma crescente centralização da Cúria romana nas decisões a respeito da santidade canonizada.

" Utilizamos o termo "grupos de pressão" no mesmo sentido que Delooz (DELOOZ,1976:240), ou seja, grupos que atuavam direta e indiretamente das mais diversas formas para promover o reconhecimento papal de seus candidatos a santos.

7 Segundo Gotor (2004) e Burke (1987), foram promovidos a santos 9 franciscanos e 7 dominicanos entre o século XVI e meados do XVIII.

Idéias - Rev. Inst. Filos. Ciênc. Hum. UNICAMP, v.6, n.2, p.169-194, jul/dez. 2015 
Entre os primeiros séculos da era cristã e o século XIII, os santos eram escolhidos e cultuados majoritariamente por grupos locais, e reconhecidos oficialmente pelos bispos, sem a necessidade de processosinstitucionais. Mesmo após a determinação da prerrogtiva papal, muitos santos continuaram sendo reconhecidos e cultuados dessa maneira. No entanto, uma mudança radical se fez notória a partir de 1588, com a criação da Sagrada Congregação dos Ritos, responsável pela condução dos processos de canonização, entre outras funções. Progressivamente observou-se a complexificação jurídica dos processos, principalmente a partir do papado de Urbano VIII (1623-1644). Sem dúvida, parte da explicação para a mudança tem sua origem nas críticas protestantes à santidade católica. A resposta da Santa Sé começou a ser formulada no Concílio de Trento (1545-1563), e consistiu não só na confirmação do culto aos santos e na reafirmação dos sentidos teológico e religioso da santidade. Resultou, a longo prazo, na implementação de um amplo e rigoroso sistema que deveria prover fundamentos históricos, teológicos e jurídicos seguros para o reconhecimento oficial da santidade de cada membro, novo ou antigo, do panteão católico (DELOOZ, 1976). Não por acaso as canonizações foram suspensas por 65 anos ao longo do século XVI e no século seguinte a rigorosa burocracia canonizadora produziu apenas 24 santos e santas. Os longos e detalhados processos eclesiásticos tinham início com um ou vários processos informativos diocesanos, organizados por iniciativa local, para informar a Santa Sé sobre a fama de santidade do candidato. Se reconhecidos como válidos pela Congregação dos Ritos, o papa autorizava a introdução oficial da causa. Seguiam-se então processos apostólicos, desenvolvidos nos locais em que o candidato nasceu, viveu e morreu, e realizados por delegados nomeados pelo papa. Nessa etapa tomavam-se os depoimentos das testemunhas sobre a vida, as virtudes e os milagres do candidato. Cópias dos inquéritos seguiam para Roma e eram examinadas por parte dos cardeais da Congregação, cujo relatório sobre a causa servia de base para o papa tomar sua decisão final (GAJANO, 1999). 
Cumprir tão longa maratona e fazer girar as engrenagens da "fábrica de santos" tornou-se cada vez mais difícil. As simples mobilizações e pressões de grupos locais e dioceses já não eram mais suficientes. Canonizar tornava-se mais do que nunca uma questão de estratégia e pressão política. A Companhia de Jesus conseguiu promover no século XVII a canonização de três de seus membros e a beatificação de cinco deles ${ }^{8}$. Seus três primeiros santos, Inácio de Loyola, Francisco Xavier e Francisco Bórgia, eram espanhóis e tiveram suas causas beneficiadas por contarem com a eficiente pressão de grupos de apoiadores formados por aristocratas, famílias importantes e pelos próprios monarcas ibéricos, Felipe II e Felipe III 9 .

O "lobby" feito pelos promotores de um novo culto, fosse nas regiões de origem e atuação do candidato a santo, fosse em Roma, junto ao papa, cardeais e auditores responsáveis pelo julgamento, era apenas uma das estratégias utilizadas. A produção e publicação de biografias de caráter hagiográfico, as chamadas "vidas devotas", do pretendente aos altares também se constituiu como indício e elemento de propaganda das campanhas de canonização.

A impressão de "vidas devotas" e das hagiografias normalmente cumpria uma dupla função, edificante e pedagógica, ao divulgar, através da história de um indivíduo, modelos de comportamentos para os fiéis. Mas não apenas. Muitas delas eram produzidas por ordens religiosas interessadas em reforçar ou em sistematizar e legitimar suas próprias identidades, associadas a

8 Os beatificados foram Luis Gonzaga, Stanislau Kostka, e os três mártires japoneses: Paolo Miki, Giovanni de Goto e Giacomo Kisai. Ver O’Neill e Domínguez (2002).

9 Loyola e Xavier foram canonizados em 1622, na mesma cerimônia que elevou aos altares outros dois espanhóis, Isidoro de Sevilha e Teresa de Ávila; Francisco Borgia em 1671. Ver Dandelet (2001). De acordo com Burke (1987) a bula que canonizou Inácio de Loyola mencionava as requisições tanto de Felipe II quanto de Felipe III.

Idéias - Rev. Inst. Filos. Ciênc. Hum. UNICAMP, v.6, n.2, p.169-194, jul/dez. 2015 
ideais de santidade, ou ainda para divulgar suas ações em colégios e missões, como fizeram os jesuítas ${ }^{10}$.

Os séculos XVI e XVII assistiram a um enorme crescimento de publicações de caráter hagiográfico. $\mathrm{O}$ impulso a esse tipo de literatura também está ligado ao trabalho desenvolvido pelos chamados padres "bolandistas", jesuítas belgas que desenvolveram uma rigorosa metodologia crítica histórica e filológica para o gênero hagiográfico. Baseados em longa e meticulosa pesquisa em arquivos e bibliotecas europeus, os bolandistas iniciaram, em meados do século XVII, a publicação dos Acta Sanctorum, coleção hagiográfica organizada a partir do calendário litúrgico católico. Desde então, a metodologia e os textos dos bolandistas tornaramse referência para a escrita do gênero (ROZZO, 2002:47-49).

Desde os séculos $\mathrm{XIV}$ e XV, a literatura de caráter hagiográfico passou a integrar as campanhas dos candidatos à santidade canonizada, fornecendo dados úteis, ainda que nem sempre precisos, para os processos (ROZZO, 2002:54). Com um maior controle da Santa Sé sobre a questão da santidade, inclusive sobre as publicações relativas à mesma, as investigações sobre a vida e os milagres dos candidatos foram se tornando mais cuidadosas, até chegar à versão rigorosa da metodologia bolandista ${ }^{11}$. A primeira biografia de caráter hagiográfico era normalmente composta por alguém próximo ao morto em odor de santidade, e contava a sua vida, morte e milagres a fim de fixar a memória de suas empresas heroicas e servir de esboço para um eventual processo de canonização; uma segunda biografia, que podia ser de outro

10 As hagiografias produzidas pelas principais ordens religiosas modernas, segundo o historiador Miguel Gotor (2012), permitem um exame interessante da sua origem e da construção de suas histórias, pois celebram sua instituição e seu profundo empenho na sociedade em que operavam, concentrando-se sobretudo na figura do santo fundador.

11 O papa Urbano VIII lançou dois decretos, em 1625 e 1642, impondo que textos de caráter hagiográfico sobre supostos santos trouxessem impressa uma Protestatio esclarecendo que a opinião de santidade expressa pelo texto não era reconhecida oficialmente pela Igreja de Roma.Ver Rozzo (2002). 
autor, se unia à primeira normalmente quando a investigação era oficialmente instruída (GOTOR, 2004:63-65).

Uma breve análise quantitativa das publicações de caráter biográfico (vidas devotas, poemas edificantes, relações de vida, entre outros) no período de introdução e desenvolvimento dos processos de canonização dos três primeiros santos jesuítas nos parece útil para investigar a relação entre tais publicações e o grau de mobilização em torno de uma candidatura aos altares, bem como sua força de pressão ${ }^{12}$.

No caso de Inácio de Loyola, foram publicadas 24 biografias em 53 anos, entre o ano da sua morte e o ano da sua beatificação (1556-1609), e um total de 64 biografias em 66 anos, ou seja, entre as datas de sua morte e de sua canonização. Trata-se de praticamente uma publicação por ano, o que nos parece indício significativo de um esforço concentrado da ordem jesuítica em santificar e, portanto, glorificar uma determinada imagem e memória da Companhia através da história de vida do seu fundador. É interessante notar que entre 1610 e 1621, período entre a sua beatificação e a canonização, o empenho parece ter se intensificado com a impressão de 19 obras de caráter biográfico. Sem dúvida, parte do rápido sucesso da campanha pela canonização do religioso se explica pelo fato de Loyola se encaixar em um dos modelos de santidade predominantes no século XVII. Neste caso, trata-se do fundador de uma ordem religiosa ligada ao combate à heresia protestante e ao fortalecimento da Igreja de Roma através da difusão do cristianismo católico por meio de seus esforços de missionação ${ }^{13}$. Contudo, frente a tantos outros "modelos" canonizados neste século, como o do santo missionário e o do

12 Os dados quantitativos que são citados nesta e nas próximas páginas relativos a obras biográficas de alguns jesuítas foram extraídos de Carayon (1864) e de Sommervogel (1890).

13 Segundo Burke (1987), entre os perfis sociais mais consagrados aos altares entre os séculos XVI e XVIII eram o do fundador de ordem ou congregação religiosa, o do missionário, o do "pastor de almas", o do dedicado à caridade e o do místico. 
santo caridoso, nos parece mais importante atentar para questões conjunturais específicas ligadas ao seu reconhecimento oficial. Nesse sentido, é inegável que a publicação de tal quantidade de material biográfico expressa o alto grau de mobilização em prol da canonização de Inácio de Loyola.

Os casos de Francisco Xavier e Francisco Bórgia são semelhantes ao do fundador da Companhia de Jesus, apesar de não terem sido objeto de tantas biografias em tão pouco tempo. Ao longo de apenas 67 anos, entre 1552 e 1619, anos de morte e beatificação de Xavier respectivamente, vieram a público 16 biografias do religioso. Três anos depois, quando foi canonizado em 1622, as publicações de caráter biográfico já somavam 38 obras impressas, sete delas compartilhadas com Loyola, tornado santo no mesmo ano e na mesma cerimônia. Ainda que 13 delas sejam do ano de $1622 \mathrm{e}$, portanto, tenham um caráter mais comemorativo do que propriamente de pressão, o quantitativo de publicações anteriores não deixa de ser impressionante, principalmente se considerarmos que no curto período entre a sua beatificação e a sua canonização, ou seja, entre 1620 e 1621, sete biografias foram publicadas. O alto grau de mobilização da Companhia em promover a santidade do padre Xavier, expressa no elevado número de publicações biográficas, também se relaciona ao interesse da ordem em fixar e divulgar uma memória institucional ligada à figura do missionário ideal, pleno nas virtudes heroicas cristãs e totalmente entregue à tarefa da evangelização de hereges, pagãos e infiéis, missão maior que a própria vida. Tal modelo missionário foi abraçado pela igreja contrarreformista e passou a integrar o paradigma da santidade canonizada vigente ${ }^{14}$. Xavier tornou-se, assim, ainda em princípios

${ }_{14}$ Partindo do conceito de "Contrarreforma" como aquele que indica um conjunto de ações, institucionais e informais, de combate às reformas protestantes, de reorganização da estrutura eclesiástica e de reforço da autoridade religiosa da Igreja de Roma, nos séculos XVI e XVII, entendemos o destaque dado pela Santa Sé, através da canonização, a figuras que fortaleciam sua autoridade e sua interpretação do cristianismo, como Loyola e Xavier. No entanto, é importante apontar que a missionação jesuítica, para além do 
do século XVII, uma forte referência do modelo de missionário ideal, dentro e fora da Companhia de Jesus.

O caso de Francisco Bórgia também se adéqua em parte ao paradigma seiscentista de santidade, uma vez que tinha origem nobre e ibérica. Membro de uma importante família aristocrática espanhola, bisneto do papa Alexandre VI, exerceu ainda jovem o cargo de vice-rei da Catalunha e herdou o título de Duque de Gandía. Ingressou na Companhia quando enviuvou, aceitou o posto de cardeal e tornou-se padre geral da ordem em 1565. Apesar de ter morrido em 1572, a sua primeira biografia só veio a público vinte anos depois, e até 1624, ano de sua beatificação, foram impressas mais 15 obras sobre a sua vida. Apesar da paralisação de seu processo entre 1625 e 1647, provavelmente por conta da resistência do papa Urbano VIII à influência castelhana sobre a Santa Sé, Francisco Bórgia foi feito santo em 1671, menos de cem anos após a sua morte (DITCHFIELD, 1992:409-410). Trinta e quatro textos biográficos tinham sido publicados até então.

O contraponto desses casos bem sucedidos pode ser útil na demonstração de nosso argumento. Os jesuítas Inácio de Azevedo e Pedro Claver, mortos respectivamente em 1570 e 1654, tiveram suas causas de canonização introduzidas na Sacra Congregação dos Ritos no século XVII. O caso do martírio do padre Azevedo e seus 39 companheiros, mortos por calvinistas franceses quando estavam a caminho do Brasil, sensibilizou a assistência jesuítica portuguesa e foi comentado em diversos textos de religiosos desde 1572, sendo talvez o mais famoso deles a "Gloriosa coroa de esforçados religiosos da Companhia de Jesu mortos polla fe catholica nas conquistas dos reynos da coroa de Portugal", do padre Bartolomeu Guerreiro, publicado em Lisboa, em 1642 (MAURÍCIO, 1978:102104). A causa do processo de canonização foi introduzida em 1623 e a partir de 1628 foram sendo realizados processos informativos ordinários nas cidades do Porto, Coimbra, Braga, Évora e na

combate às heresias, buscava, através da conversão, formar no individuo um caráter cristão para sua inserção na sociedade. (O'MALLEY,1991:180-183). 
Bahia (MAURÍCIO, 1978:126-128)15. A mobilização das províncias jesuíticas portuguesa e brasileira, contudo, não se refletiu em numerosas edições biográficas ou edificantes sobre o padre Azevedo e seus companheiros. A publicação de apenas onze obras de caráter biográfico entre 1570 e 1854, quando os religiosos foram finalmente beatificados, constitui um indício significativo do pouco impacto no Vaticano das mobilizações favoráveis. A demora de 284 anos sugere, no mínimo, que o reconhecimento oficial de algum grau de santidade de Azevedo e seus companheiros não estava na pauta da Santa Sé.

O processo de beatificação do padre Pedro Claver foi registrado em Roma em 1676, o que significa que a mobilização dos grupos de apoio começara bem antes, pouco depois de sua morte em 1654, a fim de reunir testemunhos sobre sua fama de santidade. Em 1690, os grupos locais continuavam a reunir o material jurídico necessário para dar andamento ao processo, mas a beatificação só ocorreu 161 anos depois (GÓMEZ, 2007). Entre 1654 e 1851, ano em que o jesuíta foi reconhecido como beato, apenas nove biografias suas foram impressas. A análise das causas da lentidão e do insucesso prolongado das candidaturas do padre Azevedo e seus companheiros e de Pedro Claver escapam ao objetivo deste artigo, mas sem dúvida o baixo número de publicações de caráter biográfico pode ser apontado como indício da pouca força e do pouco interesse que estas causas suscitaram na Santa Sé durante os séculos XVII e XVIII.

Voltemos ao padre José de Anchieta.

Pouco tempo após a sua morte, na capitania do Espírito Santo em 1597, a província brasileira da Companhia de Jesus deu início a uma campanha de divulgação da imagem de Anchieta como varão virtuoso e santo. A primeira iniciativa partiu do então padre provincial da Companhia no Brasil, Pedro Rodrigues, que ordenou ao companheiro Quirício Caxa, mestre em Teologia Moral e ex-vice-reitor do colégio da Companhia na Bahia, que escrevesse

15 Ver ARCHIVUM ROMANUM SOCIETATIS IESU (Itália). Postulazione Azevedo, n.31. 
um relato sobre a vida e a morte do padre Anchieta. A Breve Relação da Vida e Morte do P. José de Anchieta estava pronta em 1598 e parece ter sido rapidamente divulgada em formato manuscrito entre os membros da Companhia, como conta o padre Fernão Cardim em carta ao padre Geral, Claudio Aquaviva:

No ano de mil quinhentos e noventa e oito, fui eleito na Congregação Provincial para ir tratar com V.P. cousas de importância, para bem desta província do Brasil, e entre outros papéis levei um da vida do padre José de Anchieta, cuja memória in benedictione est, escrita pelo padre Quirício Caxa conforme as informações muito certas, que o padre Pero Roiz sendo Provincial, lhe deu por escrito, de padres nossos que com o padre José trataram, em diversas casas desta costa. Foi lida nos Colégios de Portugal, em Roma e outras partes com admiração dos nossos, e causou novos desejos de perfeição, ouvirem tão raros exemplos de virtude $^{16}$ (ROIZ, 1606: 9-10).

O texto de Caxa visava informar não apenas sobre a vida e obra do padre Anchieta como também sobre a missão na província do Brasil e segue a orientação comum dos textos de divulgação das ordens religiosas à época: o objetivo da exemplaridade e a ênfase nas virtudes cristãs (SANTOS, 2001).

A segunda biografia de Anchieta, de 1606, obra encomendada pelo próprio Fernão Cardim, padre provincial do Brasil naquele momento, não por acaso é de autoria do padre Pedro Rodrigues, e dá continuidade ao esforço da província brasileira em divulgar não apenas a figura de Anchieta como as realizações e virtudes de seus membros em geral. Ao enfatizar a função exemplar da vida e das virtudes de Anchieta, o texto de Rodrigues deixa claro que se trata da divulgação da vida de um "santo".

De maneira muito mais detalhada do que fizera seu antecessor, o jesuíta narra casos que exemplificam o espírito de profecia, os milagres e a fama de santidade do padre José, e também destaca a participação direta e o papel central de Anchieta nas

16 O padre Pedro Rodrigues, em algumas cartas e textos dos séculos XVI e XVII, também é chamado de Pero Roiz.

Idéias - Rev. Inst. Filos. Ciênc. Hum. UNICAMP, v.6, n.2, p.169-194, jul/dez. 2015 
questões políticas da América Portuguesa de seu tempo, como a invasão francesa, os ataques tamoios, as alianças entre portugueses e indígenas e a ocupação do território pelos lusos.

A biografia de Pedro Rodrigues foi, sem dúvida, muito bem sucedida no propósito de propagar tanto o conhecimento da vida e da obra de Anchieta quanto em divulgar sua fama de santidade. Circulando em cópias manuscritas através de uma rede de residências e colégios jesuíticos em toda a Europa, a obra do padre serviu de base principal para traduções e novas biografias publicadas nos anos seguintes em diferentes línguas (BARBOSA, 2006) ${ }^{17}$. Desde a morte do padre José até o final do século XVII, foram escritos 24 textos de caráter biográfico, incluindo o de Caxa e o de Rodrigues, e publicados 21 deles $^{18}$. Destes, dez se tratam de traduções da obra do segundo biógrafo, que se tornou mais conhecida por conta da versão em latim preparada pelo jesuíta italiano Sebastião Beretário, então membro da província castelhana. Feita por ordem de seus superiores, como o próprio padre Beretário afirma no fim de seu texto, a tradução provavelmente já estava pronta em 1615, uma vez que a autorização para impressão dada

\footnotetext{
17 Ver também Leite (1938-1950). Até agora pudemos verificar a presença de muitas hagiografias e vidas devotas nas livrarias de alguns colégios e casas da Companhia de Jesus em Portugal, o que sugere ser um tipo de leitura bastante comum entre os membros da ordem. Nas listas dos colégios de Coimbra, Vila Nova de Portimão e Elvas encontram-se registradas quatro biografias de José de Anchieta, sendo uma de autoria do padre Sebastião Beretário e outra do padre Simão de Vasconcelos, ambas em Coimbra. ARQUIVO NACIONAL DA TORRE DO TOMBO (Portugal), Fundo MNEJ, maço 62, caixa 50, n.1.

18 Temos conhecimento até agora de vinte e uma biografias impressas no século XVII na Europa, a saber: BERETÁRIO, 1617a,1617b,1620,1621a, 1621b; PATERNINA,1618 e 1622; OUTREMANN, 1619; Autor desconhecido, 1624a, 1624b; Autor desconhecido, 1624 e 1625; SGAMBATA,1631; FLORI, 1639; ASTRIA, 1643, 1651, 1658 e 1670; MONTEYRO, 1660; VASCONCELOS, 1672; SANMARTIN, 1677. Ver Leite (1938-1950); Sommervogel (1890); Carayon (1864). Com exceção da edição em latim de 1621 e dos textos de 1622, 1631, 1660 e 1677 , todas as outras obras, incluindo as manuscritas, já foram localizadas.
} 
pelo padre Geral Muzio Vitelleschi data de fevereiro de $1616^{19}$. Apesar de apresentar cinco subdivisões internas, uma a mais que o texto de Rodrigues, a versão latina de Beretário reproduz essencialmente o conteúdo da obra do ex-provincial do Brasil. Lá estão os muitos elogios e exemplos das admiráveis virtudes heroicas cristãs de Anchieta, a narrativa de sua inspiradora atividade missionária entre índios e portugueses, e os casos sem fim que demonstram suas profecias e milagres, sinais de sua santidade. Se o intuito da província brasileira era difundir a imagem de José de Anchieta na Europa, como parece ter sido, a versão latina do texto do padre Rodrigues foi a solução mais eficaz. Sendo o latim ainda a língua oficial do mundo letrado seiscentista, as traduções em línguas locais se multiplicaram nos anos seguintes ${ }^{20}$. Não só foram impressas duas edições da tradução de Beretário em 1617, uma em Lyon e outra em Colônia, como se seguiram a versão em espanhol do também jesuíta Estevão de Paternina, publicada em 1618 e 1622, a tradução em francês por outro companheiro da ordem, Pierre d'Outreman, em 1619, uma em alemão, publicada em Ingolstatt em 1620, e duas edições em italiano, uma traduzida por um jesuíta não identificado e impressa em Turim em 1621, e outra em Messina, em 1639, cuja tradução foi feita pelo jesuíta Luigi Flori. Apesar de impressa muitos anos depois, em 1672, a biografia sobre Anchieta do padre português Simão de Vasconcelos também se baseou na obra do padre Rodrigues.

Assim sendo, nos parece que o texto do padre Pedro Rodrigues, em sua versão latina elaborada pelo padre Beretário,

19 Meum certe consilium in hac qualicunque scriptione non fuit lucem, aut fumum dare; neq; virum summis dignum laudibus exornare, sed eorum imperio parere, qui pro suo iure mihi id oneris imposuerunt...; “Sem dúvida, minha opinião não veio à luz em qualquer parte deste escrito, nem deu sinal, e não enfeitou o digno varão com os mais altos elogios, mas submeteu-se à autoridade deles, que impuseram sobre mim este fardo em nome de seu direito...". (BERETÁRIO, 1617:276. Tradução nossa)

${ }^{20}$ Nossa breve análise da importância da versão latina do padre Sebastião Beretário deve muito ao artigo de Marín e Martín (2000).

Idéias - Rev. Inst. Filos. Ciênc. Hum. UNICAMP, v.6, n.2, p.169-194, jul/dez. 2015 
rapidamente se tornou a biografia de Anchieta de referência em inícios do século XVII, promovida e divulgada pela Companhia de Jesus na Europa. Ainda que não pareçam ser versões desta biografia, as quatro pequenas publicações impressas entre 1624 e 1625, respectivamente em Nápoles, Bolonha, Paris e Bordeaux, também vieram à luz por interferência da Companhia e, é claro, trazem o mesmo discurso de defesa do status de "santo" do padre Anchieta e da validade de seus milagres ${ }^{21}$.

Contemporaneamente a esse grande número de publicações sobre o padre José na Europa, a província brasileira da Companhia dava início aos trâmites formais para iniciar o processo jurídico em prol da sua canonização. Em 1617, realizou-se a Congregação Provincial dos Jesuítas do Brasil, no colégio da Bahia, onde se formularam alguns postulados a serem enviados ao padre Geral da Ordem, em Roma. Entre eles estava o pedido da província do Brasil para que se promovesse junto à Santa Sé a introdução da causa de beatificação do padre Anchieta ${ }^{22}$. A resposta positiva da Cúria romana jesuítica não tardou, e a ordem para iniciar a preparação da causa com a realização de processos informativos foi cumprida rapidamente pelos padres do Brasil23.

De fato, muito antes dessa mobilização oficial, alguns padres da província já buscavam recolher testemunhos da fama de santidade do padre José. Entre 1602 e 1603 realizou-se um processo ordinário informativo na capitania do Rio de Janeiro, o que sugere

\footnotetext{
${ }^{21}$ No frontispício do livreto de 1624, impresso em Nápoles, vem a indicação de quem encomendou a impressão: "Stampato ad instanzia del Prefetto, e Fratelli della Congregatione di Chierici dell' Assunta nel Colleggio della Compagnia di Giesù in Napoli". BIBLIOTECA CASANATENSE (Itália). VOL.MISC. 539/5. As três publicações seguintes são reimpressões do mesmo texto.

22 "Proposita à congregatione Brasiliae provinciae ad R.P. Generalem, Anno MDCXVII". ARCHIVUM ROMANUM SOCIETATIS IESU, Congregationes Provinciales, 55, f.255-256.

23 “Responsa R P N G. Mutii Vitelleschii ad proposita Congregationes Brasiliae prod 15 Maii 1618", ARCHIVUM ROMANUM SOCIETATIS IESU, Congregationes Provinciales, 55, f.257-257v.
} 
que a intenção canonizadora de alguns dos ex-companheiros de Anchieta, como Pedro Rodrigues e Fernão Cardim, já se manifestava pouco depois da sua morte ${ }^{24}$. A elaboração das duas primeiras biografias em 1598 e em 1606 reforça a hipótese de que muito rapidamente formou-se na província um grupo bastante empenhado em fazer de Anchieta o primeiro santo jesuíta do Brasil.

É muito provável que o grande responsável pela iniciativa e divulgação da biografia sobre Anchieta do padre Rodrigues, o padre Fernão Cardim, tenha estado presente na Congregação de 1617, na condição de ex-provincial, e tenha sido um dos defensores da inclusão do postulado sobre a beatificação de Anchieta. Não por acaso, o padre Cardim foi testemunha de primeira hora quando teve início o processo informativo da Bahia, realizado em 1619.

A partir deste ponto, as etapas sucederam-se rapidamente. Entre 1619 e 1622, foram realizados processos ordinários informativos na Bahia, em Olinda, no Rio de Janeiro e em São Paulo a fim de reunir testemunhos e provas juridicamente convincentes sobre a vida, morte, milagres e fama de santidade do padre José. O material chegou à Sagrada Congregação dos Ritos, entre 1623 e 1624, e neste mesmo ano o pontífice autorizou a introdução da causa pela canonização de Anchieta ${ }^{25}$. O passo seguinte do processo,

${ }^{24}$ Consultamos o processo informativo do Rio de Janeiro de 1602 na biblioteca do Pateo do Collegio, em São Paulo. É uma fotocópia incompleta. Apesar de não haver registro de tal processo no arquivo da Congregação dos Ritos, no Vaticano, o que sugere que talvez tal escrito não tenha chegado a Roma, o padre Fernão Cardim o menciona explicitamente em sua carta ao padre Aquaviva em 1606: “... vendo eu isto, fiz menção por carta ao mesmo padre [Pedro Rodrigues] que tornando sua Reverencia a visitar a Província visse se podiam aquelas coisas do padre José confirmar mais e autorizar com testemunhos autenticos (...), pareceo bem ao padre o conselho, e quando tornei da Europa, achei em sua mão cinco feitos de testemunhos autênticos tirados juridicamente pelo prelado administrador do Rio de Janeiro...". (ROIZ, 1955:9-10)

${ }^{25}$ No índice de registros de decretos sobre Servos de Deus da antiga Congregação dos Ritos, presente no Arquivo da Congregação das causas dos 
a chamada "fase apostólica", ocorreu simultaneamente no Brasil e em Portugal entre 1626 e 1629. Mais rigorosos, por seguirem um protocolo determinado pelos tribunais da Santa Sé, os processos apostólicos foram realizados em Lisboa, Évora, São Paulo, Rio de Janeiro e Olinda. As cópias destes chegaram a Roma, mas o rápido e aparentemente bem-sucedido andamento do processo foi bloqueado em 1634. A causa foi paralisada por conta do breve papal "Caelestis Hierusalem", que estabelecia, entre outras coisas, não se poder proceder à beatificação de um servo de Deus senão após cinquenta anos de sua morte (STANO, 1979).

A publicação na Europa de treze vidas devotas de José de Anchieta entre 1617 e 1634, no mesmo período em que se desenrolou a primeira fase do seu processo de canonização, é um indício claro de que os jesuítas buscavam promover mais um companheiro ao panteão dos santos católicos. Para além das motivações específicas que impulsionavam os padres da Companhia no Brasil a obterem o reconhecimento da santidade de Anchieta, parece evidente que a evolução veloz dos processos eclesiásticos e as numerosas publicações expressam tanto a força da causa ou de interesses a ela associados, quanto a intensa mobilização de grupos de apoio e pressão na província brasileira e na Europa.

A causa foi retomada oficialmente em 1652, ano em que já havia 16 textos diferentes impressos sobre a vida e milagres de Anchieta. Apesar de boa parte das etapas exigidas pela burocracia canonizadora romana já terem sido cumpridas, o sistema jurídico havia se complexificado e impunha mais uma barreira: a comprovação da inexistência de culto público ao candidato. Entre 1656 e 1667, jesuítas e autoridades civis no Brasil, em Portugal e na Cúria romana da Ordem se mobilizaram para superar mais

santos, em Roma, aparece, em janeiro de 1623 uma referência à chegada do processo informativo feito em Pernambuco; e em janeiro de 1624, é registrada a designação do cardeal Peretti para cuidar da causa de Anchieta. ARCHIVIO DELLA CONGREGAZIONE DELLE CAUSE DEI SANTI. Index, Reg. Decr.S.D.1592-1654, f.213; f.223-224. 
este obstáculo ${ }^{26}$. No entanto, em 1668 a causa foi suspensa a pedido do postulador geral da Companhia de Jesus em Roma, só sendo retomada no início do século seguinte. Sabemos que, entre reaberturas e novas suspensões, o processo se arrastou ainda por muitos anos e só resultou na beatificação do jesuíta já no final do século XX (MOUTINHO, 1980:95-98).

No século XVII, quando teve início esse longuíssimo percurso até os altares, dezoito obras de caráter hagiográfico sobre Anchieta foram publicadas na Europa, mais especificamente entre 1617, ano da introdução da causa, e 1668, quando a mesma foi suspensa. Curiosamente, a maioria se concentrou na primeira fase do processo no século XVII, isto é, das dezoito publicações, treze ocorreram no curto período entre 1617 e 1634, quase uma por ano. Entre 1634 e 1668, um período de 34 anos, apenas cinco foram publicadas. Considerando o quantitativo de biografias devotas como instrumento de análise válido, podemos dizer que a concentração de "vidas" publicadas na primeira fase da causa é um indício importante de uma mobilização bastante considerável em torno de um processo de canonização que parecia, para os que o apoiavam e divulgavam, se encaminhar favoravelmente. Se as motivações da província jesuítica brasileira para divulgar a santidade de um membro seu perpassam pela divulgação de um projeto missionário próprio e de uma identidade religiosa específica, as questões que explicam a divulgação da figura de um suposto santo jesuíta do Brasil por companheiros da ordem, tradutores, impressores e outros eventuais colaboradores na Europa ainda devem ser exploradas (SANTOS, 2008).

A diminuição significativa do número de publicações a partir de 1634 constitui um dado interessante, pois sugere o enfraquecimento de uma campanha mais ampla pela canonização do padre. Não só pelo quantitativo, mas, geograficamente, os

26 Como demonstram as muitas cartas manuscritas reunidas em um fundo do Arquivo da Postulação Geral da Companhia de Jesus. ARCHIVIO DELLA POSTULAZIONE GENERALE DELLA COMPAGNIA DI GESÙ. Anchieta, $1032 / 42$.

Idéias - Rev. Inst. Filos. Ciênc. Hum. UNICAMP, v.6, n.2, p.169-194, jul/dez. 2015 
impressos se restringiram à península itálica, com exceção de $u^{27}$. A morosidade do processo canônico nessa segunda fase foi, sem dúvida, fruto da burocratização crescente da legislação sobre os santos, mas reforça o indício apontado pelo baixo volume de vidas devotas sobre Anchieta: a causa perdera força. As cartas trocadas entre jesuítas e autoridades civis do Brasil e os jesuítas da Cúria Romana e alguns membros da Congregação dos Ritos durante os anos 1650 e 1660 deixam claro que a campanha de canonização continuava firme por parte da província brasileira. No entanto, ser jesuíta da dita província parecia, nesse período, uma desvantagem em Roma. A guerra de restauração travada entre Portugal e Espanha desde 1640, o não reconhecimento da monarquia dos Bragança pela Santa Sé, os choques constantes entre a província jesuítica do Brasil e o governo geral da Ordem durante a década de 1660 são apenas algumas das questões que devem ser consideradas na análise da lentidão e surpreendente suspensão de uma causa que inicialmente caminhara a passos largos, como a de Anchieta.

Os casos dos jesuítas Inácio de Loyola, Francisco Xavier e Francisco Bórgia, bem como os de seus companheiros Inácio de Azevedo e Pedro Claver, nos mostram que o quantitativo de publicações de caráter hagiográfico constitui um elemento de análise importante ao considerarmos o sucesso ou o fracasso de uma candidatura à canonização no século XVII. Porém, o caso de Anchieta deixa claro que, apesar de importante, tal indício não é suficiente. Ainda que sua causa tenha contado com a atuação de grupos de apoio e pressão e com uma divulgação considerável de sua fama de santidade, através das vidas devotas publicadas ao longo do século XVII, isto não foi suficiente para garantir nem mesmo a sua beatificação.

27 Referimos-nos ao Compendio Panegyrico do P.J. Anchieta, do padre Manoel Monteyro, publicado em Lisboa em 1660. 


\section{Referências Bibliográficas}

\section{1 - Fontes documentais}

Archivio della Postulazione Generale della Compagnia di Gesù, Anchieta, 1032/42.

Archivio della Congregazione delle cause dei santi, Index, Reg. Decr. S. D. 1592-1654

Archivum Romanum Societatis Iesu, Postulazione Azevedo, n. 31.

Arquivo Nacional da Torre do Tombo, Fundo MNEJ, maço 62, caixa 50 , no. 1.

“Proposita à congregatione Brasiliae provinciae ad R.P. Generalem, Anno MDCXVII", Archivum Romanum Societatis Iesu, Congregationes Provinciales, 55, f. 255-256.

“Responsa R P N G. Mutii Vitelleschii ad proposita Congregationes Brasiliae prod 15 Maii 1618", Archivum Romanum Societatis Iesu, Congregationes Provinciales, 55, f. 257-257v.

\section{2 - Biografias de José de Anchieta}

ASTRIA, Giovanni Battista. Vita del P. Giosefo Anchieta Della Compagnia di Giesù. Bologna: Herede del Benacci, 1643; 1651; $1658 ; 1670$.

BERETARIO, Sebastião. Josephi Anchietae Societatis Jesu Sacerdotis in Brasilia defuncti Vita. Ex iis quae de eo Petrus Roterigus Societatis Jesu Praeses Provincialis in Brasilia quatuor libris Lusitanico idiomate collegit, aliisque monumentis fide dignis. Lugduni(Lyon): Sumptibus Horatij Cardon, 1617; Coloniae Agrippinae: Apud Ioannem Kinchirem sub Monocerate, 1617; [sem local], 1621.

BERETARIO, Sebastiano. Leben des Ehrwürdigen P. Jos. Anchietae der Societat Jesu Priesters. Ingolstatt, 1620. 
Breve Elogio della vita del P.Gioseffo Anceta della Compagnia di Giesu. Il quale com grido universale di Santità, e di Miracoli morì nel Brasile à 9 di Giugno 1597 dopo haver ivi speso 44 anni in predicar la S.Fede. Stampato ad instanzia del Prefetto, e Fratelli della Congregatione di Chierici dell' Assunta nel Colleggio della Compagnia di Giesù in Napoli. In Napoli, per Lazzaro Scoriggio, 1624.

CAXA, Quirício. (1598) Vida e Morte do Padre José de Anchieta. Rio de Janeiro: Secretaria Geral de Educação e Cultura, 1965.

COUTINHO, Christóvão de Sousa. Livro da Vida do bem aventurado Padre Joze de Anchieta. Com algumas Orações devotas de outros livros. Cópia manuscrita do texto de Pedro Rodrigues, 1620.

D'OUTREMANN, Pierre. La Vie Miraculeuse Du P. Joseph Anchieta de la Compagnie de Jesus: escrite em portugais par le P. Pierre Roderiges puis en latin, augmentée de beaucoup, par le P. Sebastian Beretaire, finalement traduite du latin en françois par un Religieux de la mesme Compagnie. Douay: De l'imprimerie de Marc Wyon, 1619.

Eloge du P. Joseph Anquieta de la Compagnie de Jesus. Paris: Chez Sebastien Cramoisy, 1624; Bordeaux: Pierre de la Court, 1625.

Elogio del Padre Gioseffo Anceta della Compagnia di Giesù. Il quale com grido universale di Santità, e di Miracoli morì nel Brasile à 9 di Giugno 1597 dopo haver ivi speso 44 anni in predicare la Santa Fede; come si hà da i Processi, che sono nelle Ruote Romane. In Napoli, Como, Reggio, \& in Bologna, presso Theodoro Marcheroni, e Clemente Ferroni, 1624.

FLORI, Luigi. Vita del p. Gioseppe Ancheta della Compagnia di Giesù. Scritta in lingua latina dal $p$. Sebastiano Berettari i cinque libri, e tradotta nella spagnola, e diuisa in capi dal $p$. Stefano Paternina della medesima Compagnia. Et vltimamente in questa nostra volgare italiana ridotta, dal p. Lodouico Flori dell'istessa religione. Messina: Heredi di Pietro Brea, 1639. 
MONTEYRO, Manoel. Compendio Panegyrico do P.J. Anchieta. Lisboa: [s.n.], 1660.

PATERNINA, Estevão de. Vida del Padre Joseph De Anchieta De La Compañia De Iesus, Y Provincial Del Brasil. En Salamanca: En la Emprenta de Antonia Ramirez Viuda,1618; Em Barcelona, Per Estevam Liberos, 1622.

ROIZ, Pero. (1606) Vida do Padre José de Anchieta da Companhia de Jesus. Salvador: Livraria Progresso Editora, 1955.

SANMARTIN, Baltasar de Anchieta Cabrera y. Compandio de la vida de el Apostol de el Brasil, Nuevo Taumaturgo, y grande Obrador de maravillas, V.P. Joseph de Anchieta. Jerez de la Frontera: [s.n.], 1677.

SGAMBATA, Scipião. Elogio del P. Giuseppe Anchieta della Compagnia di Gesù. Nápoles: Scoriggio 1631.

VASCONCELOS, Simão de. Vida do Venerável Padre José de Anchieta da Companhia de Jesus. Lisboa: João da Costa, 1672.

Vita del Padre Giosefo Anchieta Religioso della Compagnia Di Gesu, Apostolo del Brasil. Composta in Latino dal Padre Sebastiano Beretario della medesima Compagnia, Et nel volgare Italiano ridotta da un divoto Religioso. Turim: Per gli HH. di Gio. Dom. Tarino, 1621.

\section{3 - Instrumentos bibliográficos}

CARAYON, Auguste. (1864) Bibliographie historique de la Compagnie de Jésus. Genebra: Slatkine Reprints, 1970.

O’NEILL, Charles; DOMÍNGUEZ, Joaquín Ma. Diccionario Histórico de la Compañía de Jesús Biográfico-Temático. Roma/ Madrid: Universidad Pontificia Comilla, 2001. 4v.

SOMMERVOGEL, Carlos. Bibliothèque de la Compagnie de Jésus. Paris: A. Picard,1890-1932. 12v. 
Como fazer um santo: as biografias devotas...

\section{4 - Obras gerais}

BARBOSA, Maria de Fátima Medeiros. As letras e a cruz: pedagogia da fé e estética religiosa na experiência missionária de José de Anchieta, S.J. (1534-1597). Roma: Editrice Pontificia Università Gregoriana, 2006.

BURKE, Peter. "How to be a Counter-Reformation Saint?", The historical anthropology of early modern Italy: essays on perception and communication. Cambridge: Cambridge University Press, 1987, pp. 48-62.

DANDELET, Thomas James. Spanish Rome: 1500-1700. Virginia: YaleUniversity/R.R. Donnelley \& Sons, 2001.

DELOOZ, Pierre. "Per un studio sociologico della santità", in: GAJANO, Sofia Boesch [org.]. Agiografia altomedioevale. Bologna: Il Mulino, 1976, pp. 227-258.

DITCHFIELD, Simon. "How not to be a Counter-Reformation Saint: the attempted canonization of Pope Gregory X, 1622-1645", Papers of the British School at Rome, v. 60, 1992, pp. 379-422.

GAJANO, Sofia Boesch. La santità. Roma-Bari: Editori Laterza, 1999.

GÓMEZ, Jaime Humberto Borja.“Historiografía y hagiografía: vidas ejemplares y escritura de la Historia en el Nuevo Reino de Granada", Fronteras de la historia, v. 12, 2007, pp. 53-78.

GOTOR, Miguel. Chiesa e santità nell'Italia moderna. Roma-Bari: Editori Laterza, 2004.

. Santi Stravaganti. Agiografia, ordini religiosi e censura ecclesiastica nella prima età moderna. Roma: Aracne Editrice, 2012.

LEITE, Antonio Serafim. História da Companhia de Jesus no Brasil. Rio de Janeiro/Lisboa: INL/Portugália, 1938-1950. 11v. 
MARÍN, José A. Sanches; MARTÍN, Maria Nieves Muñoz. “La estructura literaria de la biografía de Anchieta escrita por Sebastiano Berettari", Actas do Congresso Internacional Anchieta em Coimbra, Colégio das Artes da Universidade, tomo II. Porto: Fundação Eng. Antônio de Almeida, 2000, pp. 721-737.

MAURÍCIO, Domingos. "Beatos Inácio de Azevedo e 39 companheiros mártires", Didaskalia, v.8, 1978, pp. 89-156.

MOUTINHO, Pe. Murillo. A causa de beatificação do pe. Anchieta. São Paulo: Edições Loyola, 1980.

O'MALLEY. John W. “Was Ignatius Loyola a Church Reformer? How to look at Early Modern Catholicism", The Catholic Historical Review, v. 77, n. 2 (abril), 1991, pp. 177-193.

ROZZO, Ugo [org.]. Il libro religioso. Milão: Edizioni Sylvestre Bonnard, 2002.

SALLMANN, Jean-Michel. "Sainteté et société", in: GAJANO, Sofia Boesch [dir.]. Santità, culti, agiografia. Temi e prospettive. Roma: Viella, 1997, pp. 327-340.

SANTOS, Zulmira Coelho dos. “Em busca do paraíso perdido: a Chronica da Companhia de Jesu do Estado do Brasil de Simão de Vasconcelos, S.J.", in CARVALHO, José Adriano de Freitas [dir.]. Quando os frades faziam História. Porto: Centro universitário de História da espiritualidade, 2001, pp.145-178.

"A literatura 'hagiográfica' no Brasil do tempo do Pe. António Vieira: da Chronica da Companhia de Jesu do Estado do Brasil e do que obrarão seus filhos nesta parte do Novo Mundo (1663) às biografias devotas de Simão de Vasconcellos", Românica, v. 17. Lisboa: Edições Cosmos, 2008, pp. 151-166.

STANO, Fr. Caietanus (Fidei Promotor Generalis), “Disquisitio Pomotoris Generalis Fidei de Causa Ven. Servorum Dei Iosephi Anchieta", Brasilien. seu S.Salvatoris. Guatimalen. Quebecen. Marianopolitan. seu Albanen. Super Dubio An ad beatificationem Ven. Servorum Dei Iosephi Anchieta, Mariae ab Incarnatione, 
Petri a S.Ioseph de Betancur, Francisci de Montmorency-Laval et Catharinae Tekakwitha, qui actuositate et sanctitate ad commune Ecclesiae Brasiliensis, Guatimalensis, et Americae Septentrionalis bonum contulerunt, procedi possit attenta et probata solida fama miraculorum. v. 2, 1979, pp. 1-20.

VAN DAMME, Stéphane. “Education, Sociability and Written Culture: the case of the Society of Jesus in France", Les Dossiers du Grihl. Disponível em http://dossiersgrihl.revues.org/752. Acesso em 03 jun. 2013, 16:30. 